\title{
THE EFFECT OF LAND USE CHANGE ON LAND SURFACE TEMPERATURE IN THE NETHERLANDS
}

\author{
S. Youneszadeh ${ }^{a}, *$, N. Amiri b,c, P. Pilesjo ${ }^{\text {a }}$ \\ a Dept. of Physical Geography and Ecosystem Science, Lund University, Lund, Sweden - s.youneszadeh@ gmail.com, \\ Petter.Pilesjo@gis.lu.se \\ ${ }^{\mathrm{b}}$ Dept. of Geoinformatics, Munich University of Applied Sciences, Munich, Germany - n.amiri@hm.edu \\ ${ }^{c}$ Faculty of Geoinformation science and Earth observation, ITC, University of Twente, Enschede, The Netherlands - \\ n.amiri@utwente.nl
}

Commission VI, WG VI/4

KEY WORDS: GIS, remote sensing, MODIS, land surface temperature, LST

\begin{abstract}
:
The Netherlands is a small country with a relatively large population which experienced a rapid rate of land use changes from 2000 to 2008 years due to the industrialization and population increase. Land use change is especially related to the urban expansion and open agriculture reduction due to the enhanced economic growth. This research reports an investigation into the application of remote sensing and geographical information system (GIS) in combination with statistical methods to provide a quantitative information on the effect of land use change on the land surface temperature. In this study, remote sensing techniques were used to retrieve the land surface temperature (LST) by using the MODIS Terra (MOD11A2) Satellite imagery product. As land use change alters the thermal environment, the land surface temperature (LST) could be a proper change indicator to show the thermal changes in relation with land use changes. The Geographical information system was further applied to extract the mean yearly land surface temperature (LST) for each land use type and each province in the 2003, 2006 and 2008 years, by using the zonal statistic techniques. The results show that, the inland water and offshore area has the highest night land surface temperature (LST). Furthermore, the Zued (South)-Holland province has the highest night LST value in the 2003, 2006 and 2008 years. The result of this research will be helpful tool for urban planners and environmental scientists by providing the critical information about the land surface temperature.
\end{abstract}

\section{INTRODUCTION}

This Earth system is a complicated cycle with many interconnected components like the Earth's surface and it's interior. Naturally the Earth surface is covered by different land cover types which are mainly distributed based on the environmental and climatically patterns. By adding the rapidly increasing human population and his needs to this balanced system, we will face with many disturbances from the concept of how we change the use of land due to our needs based on its capacity or environmental impact.

Land use is defined as "the arrangements, activities and inputs people undertake in a certain land cover type to produce a change or maintain it" (FAO/UNEP, 1999). Land use is a change over the time and the most important and primary factor in land use changes is the human need. Human population as settlements and especially large urban and industrial areas could significantly modify their sounding environment. Therefore, it is critical to have a detailed information of temporal and spatial land use changes and their rate. Land use should be matched with land capability and at the same time it should respect to the environment, and global climate systems (UNEP, 1996).

The land surface temperature (LST) is the temperature of the skin surface of a land which can be derived from the satellite information or direct measurements in the remote-sensing terminology. LST is the surface radiometric temperature emitted by the land surfaces and observed by a sensor at instant viewing angles (Prata et al., 1995). This is an accurate measurement tool for indicating the energy exchange balance between the atmosphere and the Earth. The degree of land surface temperature (LST) is affected by the surface attributes, which are significantly influenced by the elevation, slope and aspect. However, topography is one of the factors that controls the soil moisture distribution and exerting an additional influence on the land surface temperature.

The Netherlands has an almost flat topography, so it can be a proper case to separate the effect of topographic factors from the land use properties on land surface temperature (LST) behaviour analysis. The combination of the land use analysis result with the mean land surface temperature (LST) can offer useful information to study the urban land use change effects in the Dutch cities.

In this study, we investigate the effects of land use change on the land surface temperature in the Netherlands provinces based on the remote sensing analysis and zonal statistic methods.

\section{DATA COLLECTION}

In this research, two different data sources were used for our analysis, which are presented in the Figure 1. The land surface temperature were available from the NASA website by MODIS Terra (temporal interval of 8 days) and the land use data

\footnotetext{
* Corresponding author
} 
provided from the land use base of the statistics Netherlands (temporal interval of 2 or 3 years).

\begin{tabular}{|c|c|c|}
\hline $\begin{array}{l}\text { 点 } \\
\text { 范 } \\
\text { 营 }\end{array}$ & 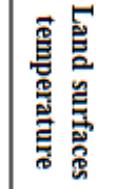 & 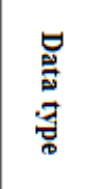 \\
\hline 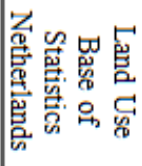 & 学 & 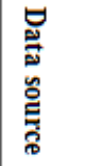 \\
\hline 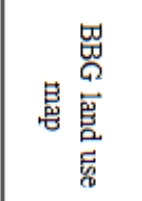 & 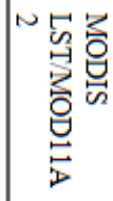 & 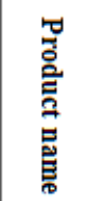 \\
\hline ' & $\begin{array}{l}\stackrel{9}{9} \\
\stackrel{9}{3}\end{array}$ & 율 물 \\
\hline 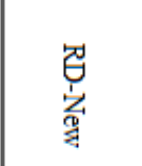 & 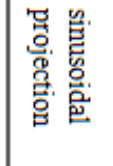 & 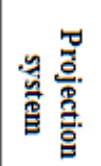 \\
\hline $\begin{array}{l}\stackrel{4}{ه} \\
\text { 啻 }\end{array}$ & 舅冤 & 氛 \\
\hline $8 \stackrel{\ddot{\dot{O}}}{\circ}$ & 홍 & 突乙 \\
\hline 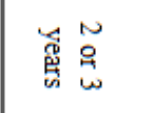 & 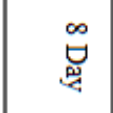 & 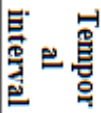 \\
\hline 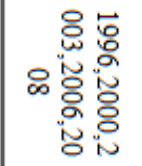 & 号 & 官苞 \\
\hline
\end{tabular}

Figure 1. Overview of the datasets

\section{METHODOLOGY}

In the global MODIS LST tiling system, the Netherlands is located in tile h18v03. This tile is gridded in a network of approximately $1 \mathrm{~km}$ by $1 \mathrm{~km}$. The BBG land use maps (updated detailed national land use map through visual analysis of aerial photography, called "Bestand Bodemgebruik") of the 2003, 2006 and 2008 years were used to assess the land use types. Multiple land uses can be present in $1 \mathrm{~km}^{2}$ LST pixel size and each of the land use classes can affect the LST mixed value. So it was needed to have the land use change maps with the same resolution as the LST images $\left(1 \mathrm{~km}^{2}\right)$ are available, including the areal proportions of each land use within each LST pixel.

Dutch BBG land use map contains 8 main classes: Traffic, Build-up areas, Semi Build-up areas, Recreational, Agricultural, Forest and natural open land, Inland waterway and offshore areas. These classes were reclassified to new categories in which different classes had different heat capacity, emissivity and reflection characteristics. The BBG land use maps were reclassed into 6 classes, using the dissolve function of Arc Map. New classes are open agriculture, build-up areas, recreational areas, greenhouse farming, inland waterway, offshore areas and forest. To summarize the values of the LST within each province and land use type and to provide tangible and practical information for decision making, zonal statistic methods were used. The spatial mean LST was then computed for all Dutch provinces and land use types. To achieve this, yearly mean LST raster files of the 2003, 2006 and 2008 years were used. Nearly 45 images for each year. To calculate the average LST of each province, the LST image values were converted to integer values, using the Int. function of the spatial analyst tool in the ArcGIS 10 software. Afterwards, the zonal statistic function was applied to calculate the mean LST.

\section{RESULTS AND DISCUSSION}

The Thermal characteristics, conductivity, albedo, surface roughness and heat capacity are among the fundamental factors which affect the amount of the LST of different land uses (Brovkin et al., 2006; Davin \& de Noblet-Ducoudré, 2010). The spatial arrangement, area, adjacent land uses and connectivity of different land uses also have impact on the mixed value of LST for each pixel. Reference (van Leeuwen et al., 2011) argued that the LST is regulated by the several parameters e.g. surface conductance, amount of water available for evaporative cooling, wind speed, and surface roughness which regulates the power of sensible and latent heat fluxes.

\begin{tabular}{|l|l|l|l|}
\hline Year & $\mathbf{2 0 0 3}$ & $\mathbf{2 0 0 6}$ & $\mathbf{2 0 0 8}$ \\
\hline $\begin{array}{l}\text { Mean LST for All the Pixels } \\
\text { with Open agriculture/ } \\
\text { Coverage percentage of the } \\
\text { land use in the pixels }>95 \%\end{array}$ & 4.45 & 5.57 & 5.49 \\
\hline $\begin{array}{l}\text { Mean LST for All the Pixels } \\
\text { with Inland waterway and } \\
\text { offshore area/ }\end{array}$ & 7.90 & 8.30 & 8.21 \\
$\begin{array}{l}\text { Coverage percentage of the } \\
\text { land use in the pixels }>95 \%\end{array}$ & & & \\
\hline $\begin{array}{l}\text { Mean LST for All the Pixels } \\
\text { with Forest/ } \\
\text { Coverage percentage of the } \\
\text { land use in the pixels }>95 \%\end{array}$ & 4.59 & 5.02 & 4.85 \\
\hline $\begin{array}{l}\text { Mean LST for All the Pixels } \\
\text { with Greenhouse farming/ } \\
\text { Coverage percentage of the } \\
\text { land use in the pixels }>80 \%\end{array}$ & 4.93 & 4.31 & 5.27 \\
\hline $\begin{array}{l}\text { Mean LST for All the Pixels } \\
\text { with Build-up area/ } \\
\text { Coverage percentage of the } \\
\text { land use in the pixels }>95 \%\end{array}$ & 6.48 & 6.98 & 6.93 \\
\hline
\end{tabular}

Table 1 . The average of mean yearly night LST for different land use types in the 2003, 2006 and 2008 years 
Table 1 shows that the lowest LST in 2003 year is observed in open agriculture, followed by forest, greenhouse farming, buildup areas, inland waterway and offshore areas. The 2006 year pattern is slightly different, where the lowest LST is found in greenhouse farming, followed by forest, open agriculture, buildup areas, inland waterway and offshore areas. In 2008 year, the lowest LST is for forest followed by greenhouse farming, open agriculture, build-up areas, inland waterway and offshore area.

These results are consistent with the study of Weng et al., in 2004 (Weng, Lu, \& Schubring, 2004). They suggest that the higher biomass/vegetation abundance a land cover has, the lower the land surface temperature is. Furthermore, vegetative land uses possessed a smaller mean value than inland water and build-up area. Forest has the least LST. This result may be explained by the fact that forests strong vegetation can decrease the amount of heat stored in the soil and surface structures through the transpiration (Weng \& Lu, 2008). A possible explanation for this is argued by Qian et al., in 2006 (Qian, Cui, \& Chang, 2006). They discussed that these changes can stem from the discrepancy in solar illumination, atmospheric influences, and soil moisture content in the different study years.

Table 2 indicates the annual mean value of the LST for different provinces for the 2003, 2006 and 2008 years. Zued-Holland has the highest LST value in the 2003, 2006 and 2008 years. The range of LST for the year 2003 is from 3.39 to $6.39^{\circ}{ }^{\circ}$. In the 2006 year, it is ranging from 4.02 to $7.21{ }^{\circ} \mathrm{C}$. The range for 2008 year is from 4.15 to $7.05{ }^{\circ} \mathrm{C}$. The mean LST value for each province can be an appropriate decision-making factor and an environmental warning tool for urban and environmental planners.

\begin{tabular}{|l|l|l|l|}
\hline & $\begin{array}{l}\text { Mean } \\
\text { LST }\left({ }^{\circ} \mathbf{C}\right), \\
\mathbf{2 0 0 3}\end{array}$ & $\begin{array}{l}\text { Mean } \\
\text { LST }\left({ }^{\circ} \mathbf{C}\right), \\
\mathbf{2 0 0 6}\end{array}$ & $\begin{array}{l}\text { Mean LST } \\
\left({ }^{\circ}\right), \mathbf{2 0 0 8}\end{array}$ \\
\hline Groningen & 4.38 & 5.99 & 5.93 \\
\hline Drenthe & 4.37 & 5.81 & 5.48 \\
\hline Overijssel & 4.42 & 5.39 & 5.46 \\
\hline Gelderland & 4.78 & 5.39 & 5.40 \\
\hline Nord-Brabant & 5.83 & 6.64 & 6.62 \\
\hline Limburg & 5.84 & 6.68 & 6.57 \\
\hline Friesland & 4.21 & 5.49 & 5.39 \\
\hline Nord-Holland & 5.83 & 6.78 & 6.68 \\
\hline Zued-Holland & 6.30 & 7.21 & 7.05 \\
\hline Zeeland & 6.24 & 6.97 & 6.79 \\
\hline Utrecht & 5.00 & 5.74 & 5.76 \\
\hline Flevoland & 3.39 & 4.02 & 4.15 \\
\hline
\end{tabular}

Table 2. The mean night LST value for each province

The zonal map of the 2006 year is provided. See Figure 1 which shows the average of the mean yearly night LST for each province. The values are the LST original raw values. To convert to Celsius, each value should be multiplied by 0.02 and subtracted from the 273.15 (Zhengming, 2007). The Zued-
Holland for all the three years has the largest mean yearly LST. Nord-Holland and Nord-Brabant are among the high LST provinces. The most urbanized parts of the country is Randstad which comprises the major cities of Amsterdam, Rotterdam, Utrecht and The Hague has around 5 million inhabitants (de Nijs et al., 2004). It can be noted that in the hot urbanized spots, the amount of mean LST is higher. Reference Zhou \& Wang in 2011, (Zhou \& Wang, 2011) argued that "apart from land-use change, urbanization with increased human population also contributes to the urban thermal environment change with the rising anthropogenic heat discharge."

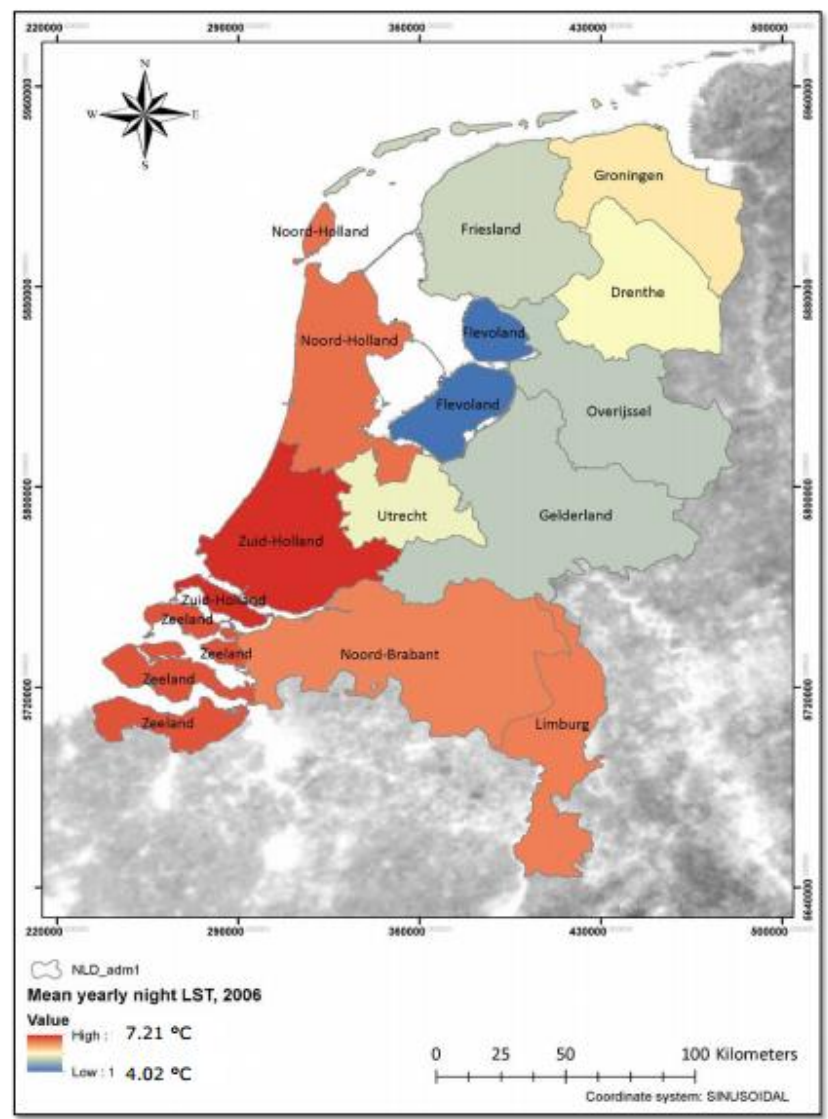

Figure 1 . The up-scaled mean yearly night LST mean to the Dutch provinces scale in 2006 year

\section{CONCLUSIONS}

The above discussion has evaluated the effect of different land use types on the land surface temperature. The mean yearly value of LST is calculated. This value can serve as a suitable managerial tool for urban planner and environmental scientists. Combining the result of land use analysis and mean LST can offer useful information to study urban heat island in the Dutch cities. Zued-Holland has the highest amount of LST from 2003 to 2008 years. The amount of LST for this province has increased from 2003 to 2008 years by $0.75{ }^{\circ} \mathrm{C}$ which could be due to urbanization, population increase and also possible variations in weather temperature. In the same period, Flevoland which has the minimum amount of LST is also increased from the $3.39{ }^{\circ} \mathrm{C}$ in the 2003 year to the $4.15{ }^{\circ}$ in the 2008 year. The amount of LST for different land use types can be used for constructing the thermal environment of the Dutch provinces in relation to the land use types. 


\section{ACKNOWLEDGEMENTS}

Our thanks to ACM SIGCHI for allowing us to modify templates they had developed.

\section{REFERENCES}

Brovkin, V., Claussen, M., Driesschaert, E., Fichefet, T., Kicklighter, D., Loutre, M. F., . . . Sokolov, A. (2006). Biogeophysical effects of historical land cover changes simulated by six Earth system models of intermediate complexity. Climate Dynamics, 26(6), 587-600. doi: 10.1007/s00382-005-0092-6

Davin, E. L., \& de Noblet-Ducoudré, N. (2010). Climatic Impact of Global-Scale Deforestation: Radiative versus Nonradiative Processes. Journal of Climate, 23(1), 97-112. doi: 10.1175/2009JCLI3102.1

de Nijs et al. (2004). Constructing land-use maps of the Netherlands in 2030. Journal of Environmental Management, 72(1-2), 35-42. doi: http://dx.doi.org/10.1016/j.jenvman.2004.03.015

FAO/UNEP. (1999). Terminology for Integrated Resources Planning and Management. Food and Agriculture Organization/United Nations Environmental Program,

Table 3 -FAO. Rome, Italy and Nairobi, Kenya

Prata, A. J., Caselles, V., Coll, C., Sobrino, J. A., ., \& Ottlé, C. (1995). Thermal remote sensing of land surface temperature from satellites: Current status and future prospects. Remote Sensing Reviews, 12(3-4), 175224. doi: 10.1080/02757259509532285

Qian, L.-X., Cui, H.-S., \& Chang, J. (2006). Impacts of Land Use and Cover Change on Land Surface Temperature in the Zhujiang Delta1. Pedosphere, 16(6), 681-689. doi: http://dx.doi.org/10.1016/S1002-0160(06)601033

UNEP. (1996). Our land our future. FAO/AGLS.Rome. 48. P.

van Leeuwen, T. T., Frank, A. J., Jin, Y., Smyth, P., Goulden, M. L., van der Werf, G. R., \& Randerson, J. T. (2011). Optimal use of land surface temperature data to detect changes in tropical forest cover. Journal of Geophysical Research: Biogeosciences, 116(G2), n/an/a. doi: 10.1029/2010JG001488

Weng, Q., \& Lu, D. (2008). A sub-pixel analysis of urbanization effect on land surface temperature and its interplay with impervious surface and vegetation coverage in Indianapolis, United States. International Journal of Applied Earth Observation and Geoinformation, 10(1), 68-83. doi: http://dx.doi.org/10.1016/j.jag.2007.05.002

Weng, Q., Lu, D., \& Schubring, J. (2004). Estimation of land surface temperature-vegetation abundance relationship for urban heat island studies. Remote Sensing of Environment, 89(4), 467-483. doi: http://dx.doi.org/10.1016/j.rse.2003.11.005

Zhengming, W. (2007). Collection-5-MODIS Land Surface Temperature Products-Users' Guide. ICESS, University of California, Santa Barbara.

Zhou, X., \& Wang, Y.-C. (2011). Dynamics of Land Surface Temperature in Response to Land-Use/Cover Change. Geographical Research, 49(1), 23-36. doi: 10.1111/j.1745-5871.2010.00686.x 